\title{
Penerapan Metode Triple Exponential Smoothing Pada Sistem Prediksi Keuntungan Bisnis Ayam Broiler Guna Meningkatkan Pengelolaan Keuangan Peternak (Studi Kasus Peternakan Ayam Wilayah Kecamatan Jatipuro Kabupaten Karanganyar)
}

\author{
Rifa'i, M.F. ${ }^{1}$; Sudirman, Yoga D. M. ${ }^{2}$; Kusuma, Dine T. ${ }^{3}$ \\ ${ }^{1,2,3}$ Sekolah Tinggi Teknik PLN \\ ${ }^{1}$ m.farid@sttpln.ac.id
}

\begin{abstract}
ABSTRAK
Prediksi keuntungan bisnis ayam digunakan untuk membantu peternak ayam dalam meramalkan keuntungan yang diperoleh di panen selanjutnya. Dengan adanya sebuah prediksi keuntungan, peternak dapat melakukan antisipasi apabila di panen selanjutnya mengalami untung sedikit atau gagal panen. Selain itu,agar peternak tetap memiliki modal usaha dan tidak mengalami tutup kandang (bangkrut). Di dalam penelitian ini penulis membandingkan dua metode yang cocok digunakan dalam kasus ini, yaitu metode triple exponential smoothing. Data yang digunakan dalam perhitungan yaitu data keuntungan pada panen sebelumnya. Untuk mengetahui nilai kecocokan kedua metode tersebut penulis menggunakan mean absolute percentage error (MAPE) untuk mengetahui persentase nilai eror. Berdasarkan pencarian nilai MAPE, metode triple exponential smoothing menghasilkan nilai MAPE sebesar $12.10 \%$ dengan nilai $\alpha=0.3$. Sedangkan dengan percobaan mencari nilai prediksi keuntungan untuk 2 panen selanjutnya diperoleh selisih sebesar Rp. 19,935,410.
\end{abstract}

Kata Kunci: Peramalan, Triple Exponential Smoothing, Monte Karlo, Prediksi, Ayam Boiler

\begin{abstract}
The prediction of the profitability of the chicken business is used to help chicken farmers in predicting the profits obtained in the future. With the prediction of victory, breeders can anticipate payments at harvest then add a little profit or crop failure. In addition, for farmers to still have business capital and do not need to close the cage (bankrupt). In this study, the authors compared two suitable methods used in this case, the triple exponential smoothing method. The data used in the calculation is the acquisition data on the previous harvest. To determine the suitability of the two methods, the writer uses the average percentage of absolute error (MAPE) to find out the percentage error value. Based on the search for MAPE values, the triple exponential smoothing method produces a MAPE value of $12.10 \%$ with a value of $\alpha=0.3$. While with the added value of estimated profits for the next 2 revenues, a difference of $R p .19,935,410$.
\end{abstract}

Keyword: Forecasting, Triple Exponential Smoothing, Monte Carlo, Prediction, Broilers 


\section{KILAT}

Vol. 8, No. 2, Oktober 2019, P-ISSN 2089-1245, E-ISSN 2655-4925

\section{PENDAHULUAN}

Peneliti telah melakukan wawancara kepada 10 peternak ayam di wilayah Kecamatan Jatipuro, Kabupaten Karanganyar. Hasil dari wawancara tersebut adalah peternak hanya dapat menghitung keuntungan yang didapat ketika sudah masa panen. Koefisien lain seperti operasional harian dan biaya penjualan yang tidak dapat diprediksi menjadi masalah berkelanjutan disebabkan keuntungan yang semu tanpa adanya perhitungan yang matematis dan sistematis. Berdasarkan pemaparan di atas keuntungan yang diperoleh peternak ayam tidak tetap turun naik sesuai keadaan musim yang ada, sehingga penulis menggunakan metode Triple Exponential Smoothing dimana metode ini digunakan untuk mengurangi ketidakaturan musiman dari data masa lalu melalui tiga tahap proses perata-rataan (penghalusan) terhadap data sebelumnya. Penerapan metode dapat memberikan informasi yang akurat mengenai perhitungan prediksi. Sedangkan untuk melihat tingkat kesalahannya akan digunakan Mean Absolute Percentage Error (MAPE). Metode pengukuran ini menemukan kesalahan absolut setiap periode tersebut, kemudian membaginya dengan nilai observasi pada periode tersebut dan terakhir merata-ratakan persentase absolut ini. [1] Berdasarkan uraian diatas maka penulis memiliki tujuan untuk menampilkan hasil prediksi keuntungan peternak sehingga dapat menjadi pedoman dalam mengelola peternakannya. Penelitian ini juga bermanfaat bagi peternak dalam mengembangkan bisnisnya dengan mengimplementasikan teknologi sebagai salah satu basis solusi. Diharapkan dengan menggunakan aplikasi ini kesejahteraan para peternak dapat bertambah dan dapat mengembangkan bisnisnya lebih terukur dan terarah sesuai dengan data.

\section{STUDI PUSTAKA}

Terdapat beberapa penelitian serupa yang menggunakan Triple Exponential Smoothing dan MAPE untuk melakukan peramalan secara time series. Adapun penelitian yang telah dilakukan tersebut adalah sebagai berikut. Sistem peramalan ini membantu manajemen apotek dalam mengelola data penjualan dan menggali informasi untuk menentukan pengadaan stok obat yang tepat dan akurat. Metode yang digunakan untuk menggali informasi yang tersimpan dalam data penjualan obat pada periode sebelumnya yaitu metode Triple Exponential Smoothing dengan pola data deret berkala. Keakuratan maksimal aplikasi ini dalam menentukan perkiraan penjualan obat mencapai 98,15\%. [2] Pada penelitian lain dilakukan peramalan jumlah penumpang pada Siluet Tour and Travel. Tujuan dari peramalan ini agar para pelaku wirausaha tidak mengalami kerugian ketika jumlah penumpang sedikit dan mengantisipasi dengan cara meramalkan jumlah penumpang untuk mengetahui banyak atau sedikitnya jumlah penumpang di bulan berikutnya. Metode yang digunakan pada penelitian ini yaitu metode Triple Exponential Smoothing. Hasil dari pengolahan dataset digunakan untuk perhitungan proses ramalan yang menghasilkan $M A P E=9,86$ alpha=0,4 $\mathrm{m}=1$ dengan hasil peramalan jumlah penumpang pada bulan November 2015 adalah 501. [3] Tujuan dari peramalan penjualan agar tidak terjadi penumpukan stok di gudang UD ACHMAD JAYA. Karena jika terjadi penumpukan stok akan mempengaruhi jumlah pembelian atau order ulang di bulan berikutnya. Metode yang digunakan untuk meramalkan adalah metode Triple Exponential Smothing. Dengan menggunakan sistem statistika khususnya Triple Exponential Smoothing dibuat perancangan sistem peramalan stok barang pada UD ACHMAD JAYA berdasarkan data penjualan obat. Hasil 
peramalan dibulan berikutnya Januari tahun 2015 adalah 194,60 dengan alpha 0,1 dan nilai kesalahan dalam peramalan atau MAPE 29,29. [4]

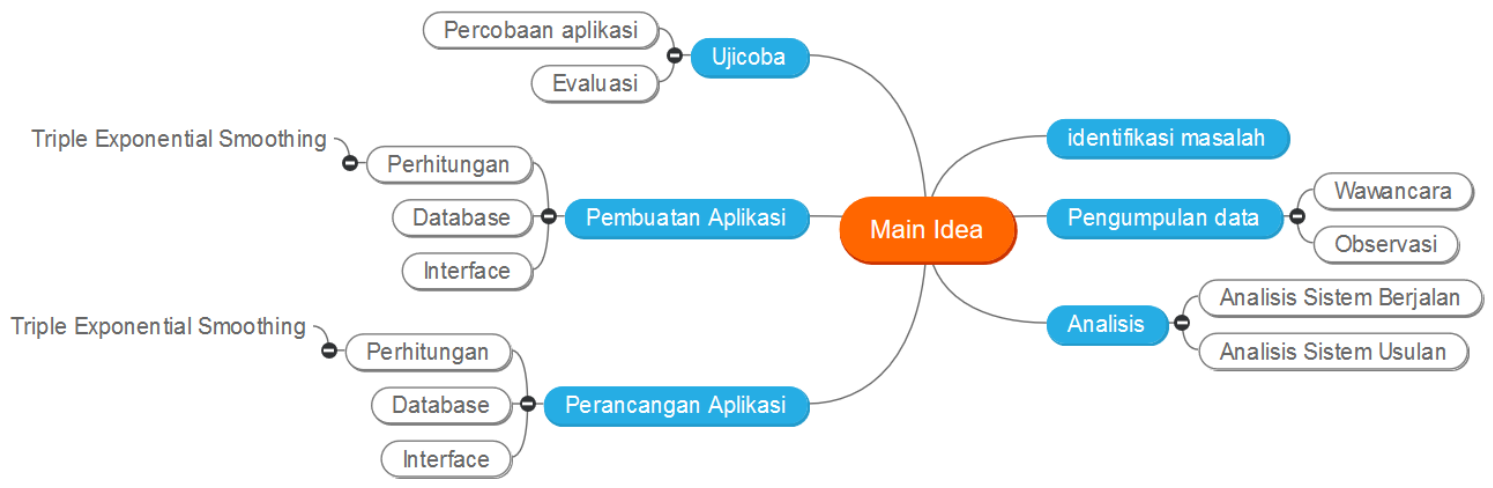

Gambar 1. Metode Penelitian

\section{METODE PENELITIAN}

Langkah-langkah penelitian ini akan disampaikan dengan menggunakan mindmap sepeti yang digambar 1. Dalam pengembangan aplikasi akan mengikuti kaidah dari extreme programming (XP) yang dimana langkah-langkahnya adalah sebagai berikut:

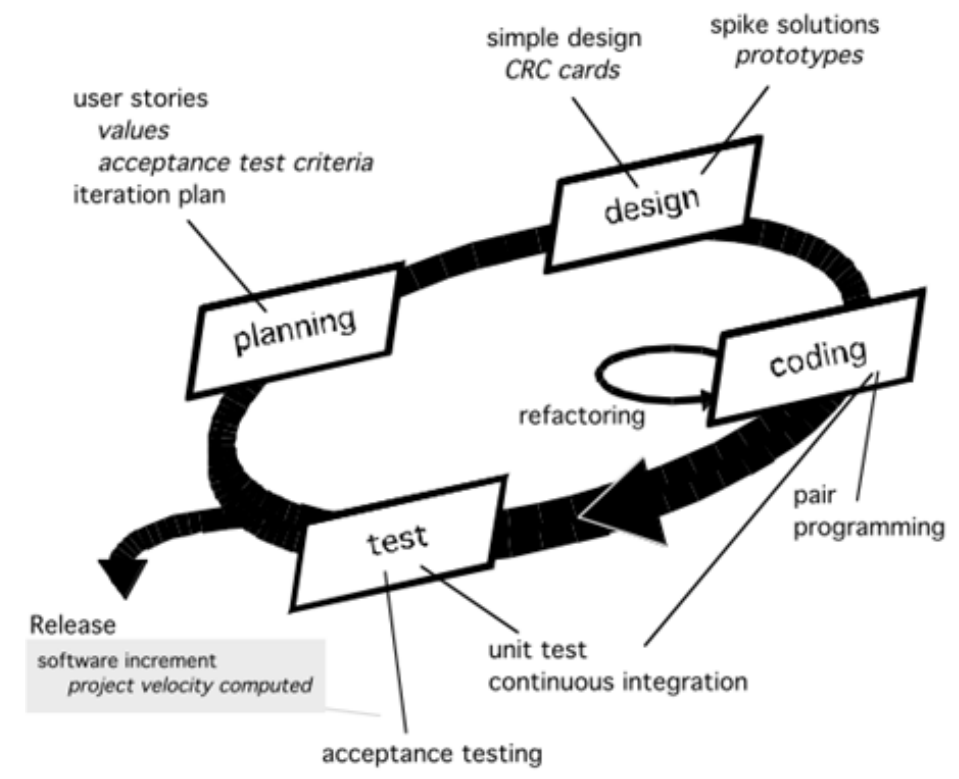

Gambar 2. SDLC pengembangan aplikasi [6]

Exponential Smoothing adalah metode time series dimana data dari waktu ke waktu di perhalus secara exponensial baik dengan menetapkan meningkatkan dan menurunkan bobot exponensial dengan data-data. Exponential Smoothin terdiri dari 3 jenis yaitu Single Exponential Smoothing, Double atau Holt's Exponential Smoothing dan Triple atau Winters Exponential Smoothing. [6] Dengan algoritma perhitungan sebagai berikut: 


\section{KILAT}

Vol. 8, No. 2, Oktober 2019, P-ISSN 2089-1245, E-ISSN 2655-4925

$$
\begin{aligned}
& \mathrm{S}_{\mathrm{t}}{ }^{\prime}=\alpha \mathrm{Xt}+(1-\alpha) \mathrm{S}_{\mathrm{t}-1}{ }^{\prime} \\
& \mathrm{S}_{\mathrm{t}}{ }^{\prime}=\alpha \mathrm{S}_{\mathrm{t}}{ }^{\prime}+(1-\alpha) \mathrm{S}_{\mathrm{t}-1}{ }^{\prime}, \\
& \mathrm{S}_{\mathrm{t}}{ }^{\prime \prime}=\alpha \mathrm{S}_{\mathrm{t}}{ }^{\prime \prime}+(1-\alpha) \mathrm{S}_{\mathrm{t}-1}{ }^{\prime}, \\
& \mathrm{a}_{\mathrm{t}}=3 \mathrm{~S}_{\mathrm{t}}{ }^{\prime}-3 \mathrm{~S}_{\mathrm{t}}{ }^{\prime}+\mathrm{S}_{\mathrm{t}-1}{ }^{\prime}, \\
& \mathrm{b}_{\mathrm{t}}=\alpha / 2(1-\alpha)^{2}\left[(6-5 \alpha) \mathrm{S}_{\mathrm{t}}{ }^{\prime}-(10-8 \alpha) \mathrm{S}_{\mathrm{t}}{ }^{\prime \prime}+(4-3 \alpha) \mathrm{S}_{\mathrm{t}}{ }^{\prime \prime}\right] \\
& \mathrm{c}_{\mathrm{t}}=\alpha 2 /\left(1-\alpha^{2}\right)\left[\mathrm{S}_{\mathrm{t}}{ }^{\prime}-2 \mathrm{~S}_{\mathrm{t}}{ }^{\prime \prime}+\mathrm{S}_{\mathrm{t}}{ }^{\prime \prime}\right] \\
& \mathrm{F}_{\mathrm{t}+\mathrm{m}}=\mathrm{a}_{\mathrm{t}}+\mathrm{b}_{\mathrm{t}} \mathrm{m}+1 / 2 \mathrm{c}_{\mathrm{t}} \mathrm{m}^{2}
\end{aligned}
$$

Dalam Perhitungan MAP menggunakan rumus sebagai berikut : [1]

$$
M=\frac{100 \pi}{n} \sum_{i=1}^{n}\left|\frac{4-\pi}{4}\right|
$$

\subsection{Perencanaan}

Berikut ini merupakan flowchart hasil dari observasi sistem yang sedang berjalan pada peternak ayam.

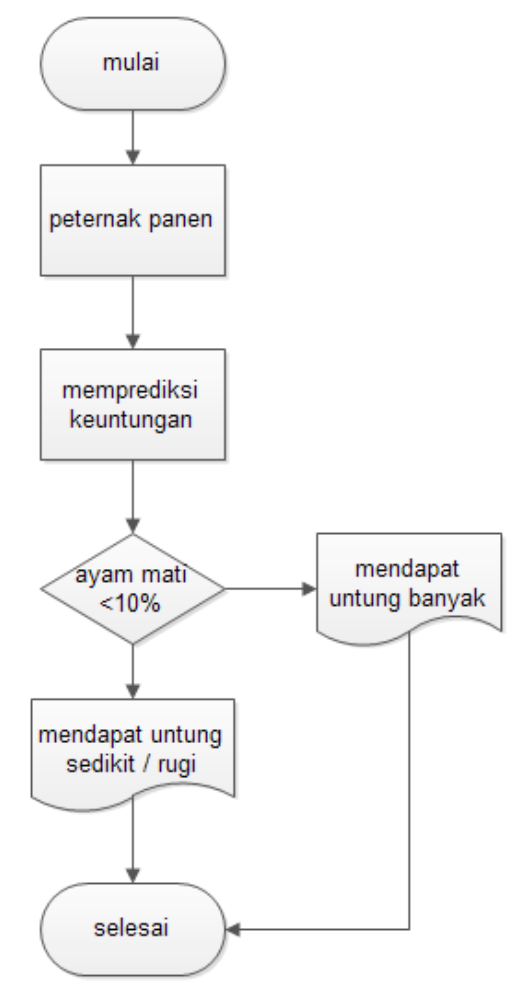

Gambar 3. Obsevasi Cara Peternak Menghitung Keuntungan

Setelah dilakukan modifikasi dari sistem yang telah berjalan, maka penulis mengubah prosesnya sebagai berikut: 


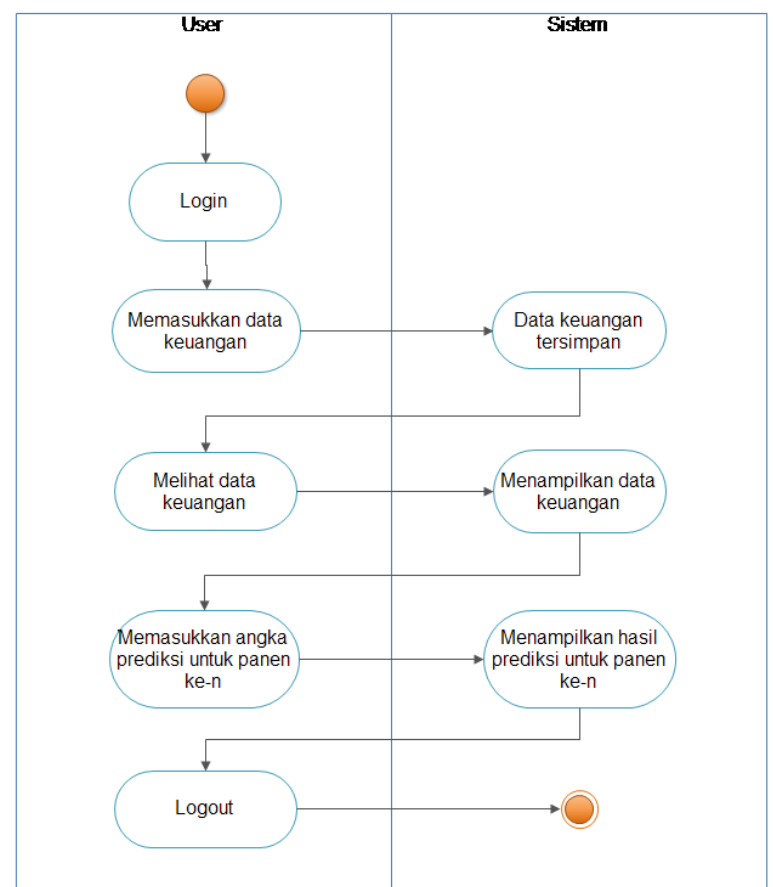

Gambar 4. Proses alur yang diusulkan

\subsection{Perancangan}

Dalam perancangan aplikasi ini menurut kaidah XP yaitu menggunakan $C R C$ card namun pada penelitian ini menggunakan tools State Transition Diagram (STD) dalam perancangannya. Terdapat 2 jenis fitur utama pada aplikasi ini yakni fitur data keuangan dan fitur prediksi.

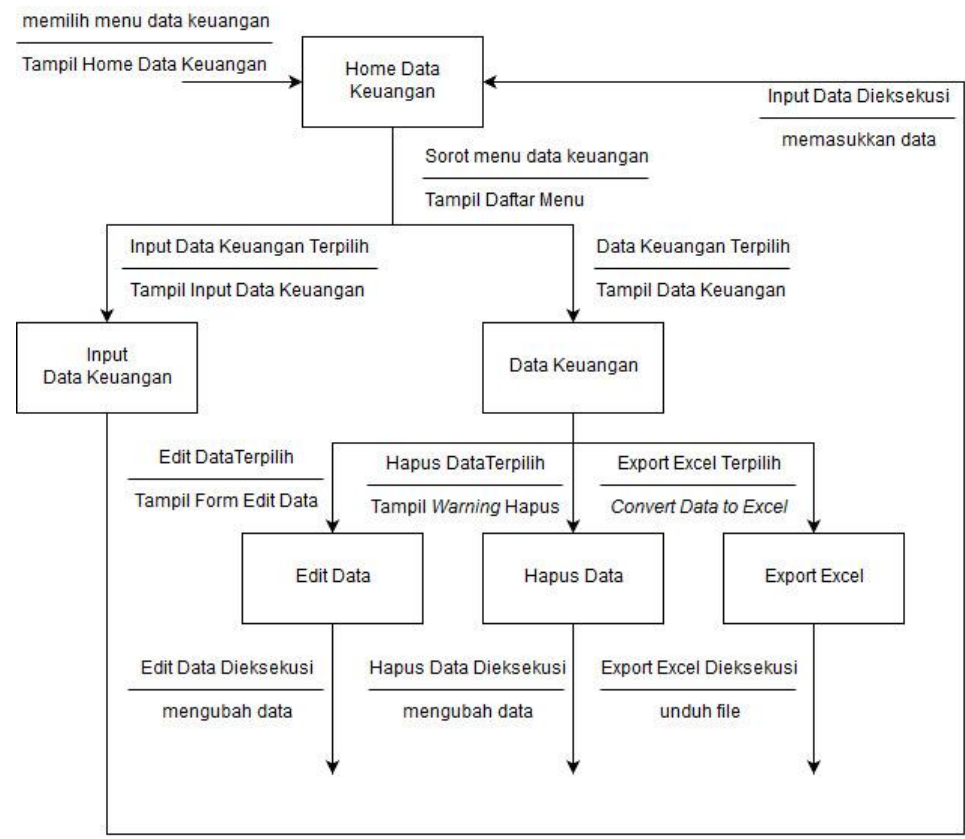

Gambar 5. STD Fitur data Keuangan 


\section{KILAT}

Vol. 8, No. 2, Oktober 2019, P-ISSN 2089-1245, E-ISSN 2655-4925

Gambar 5 menunjukkan fitur yang terdapat pada halaman data keuangan yang mana terdapat export excel yang memudahkan analisis berkelanjutan. Selanjutnya fitur prediksi sesuai dengan gambar 6 dibawah ini:

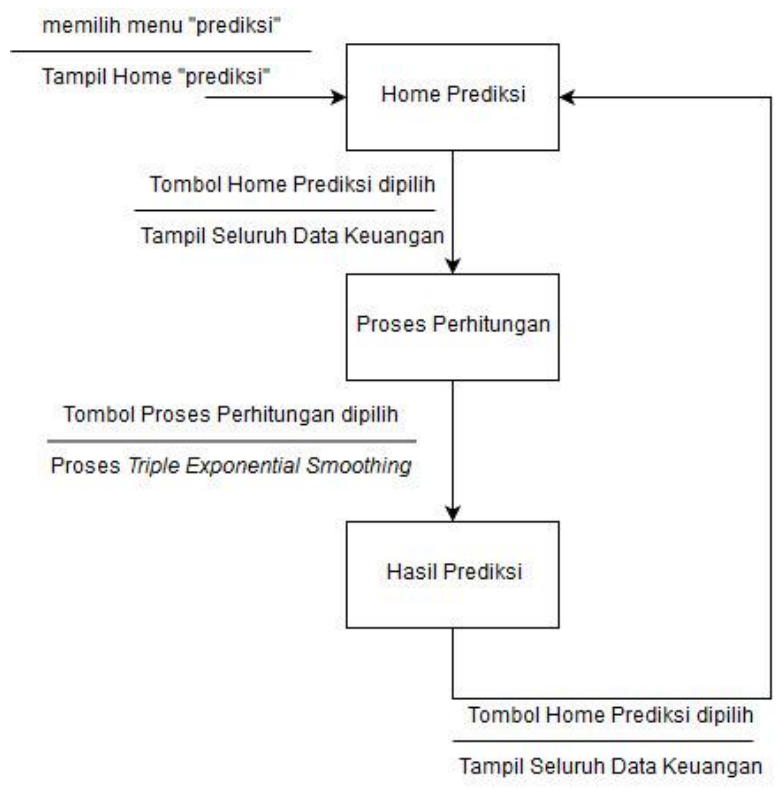

Gambar 6. STD fitur Perhitungan Prediksi

\subsection{Pengkodean}

Sesuai dengan rancangan pada gambar 5 dan 6 berikut adalah pengkodean dalam proses perhitungan Triple Exponential Smoothing pada gambar 6. Adapun list code-nya adalah sebagai berikut:

$\%$ Recover alpha, beta and gamma from PARAM

alpha $=\operatorname{param}(1)$;

beta $=\operatorname{param}(2) ; \operatorname{gamma}=\operatorname{param}(3)$;

$\%$ Initialize $\mathrm{L}, \mathrm{T}, \mathrm{S}$ and $\mathrm{FX}$ vectors

$\mathrm{L}=\operatorname{zeros}(\operatorname{size}(\mathrm{x})) ; \mathrm{T}=\mathrm{L} ; \mathrm{S}=\mathrm{L} ; \mathrm{fx}=\mathrm{L}$;

$\%$ Set initial values of $\mathrm{L}, \mathrm{T}$ and $\mathrm{S}$

$\mathrm{L}(\mathrm{s})=\operatorname{sum}(\mathrm{x}(1: \mathrm{s})) / \mathrm{s}$;

$\mathrm{T}(\mathrm{s})=\operatorname{sum}(\mathrm{x}(\mathrm{s}+1: 2 * \mathrm{~s})-\mathrm{x}(1: \mathrm{s})) / \mathrm{s}^{\wedge} 2$;

$\mathrm{S}(1: \mathrm{s})=\mathrm{x}(1: \mathrm{s})-\mathrm{L}(\mathrm{s})$;

$\%$ Iterate to compute $\mathrm{L}(\mathrm{t}), \mathrm{T}(\mathrm{t}), \mathrm{S}(\mathrm{t})$ and $\mathrm{FX}(\mathrm{t})$

for $\mathrm{t}=(\mathrm{s}+1)$ :(length $(\mathrm{x})-1)$

$$
\begin{aligned}
& \mathrm{L}(\mathrm{t})=\text { alpha* }(\mathrm{x}(\mathrm{t})-\mathrm{S}(\mathrm{t}-\mathrm{s}))+(1-\mathrm{alpha}) *(\mathrm{~L}(\mathrm{t}-1)+\mathrm{T}(\mathrm{t}-1)) \\
& \mathrm{T}(\mathrm{t})=\text { beta }^{*}(\mathrm{~L}(\mathrm{t})-\mathrm{L}(\mathrm{t}-1))+(1-\text { beta }) * \mathrm{~T}(\mathrm{t}-1) \\
& \mathrm{S}(\mathrm{t})=\text { gamma* } \\
& \mathrm{fx}(\mathrm{t}(\mathrm{t})-\mathrm{L})=\mathrm{L}(\mathrm{t})+\mathrm{t})+(\mathrm{T}(\mathrm{t})+\mathrm{S}(\mathrm{t}-\mathrm{s}+1)
\end{aligned}
$$

end

$\%$ Compute MAE + a penalty for parameters beyond the admitted range,

$\%$ i.e., $0<$ alpha, beta, gamma $<1$. The latter is required for

$\%$ parameter estimation.

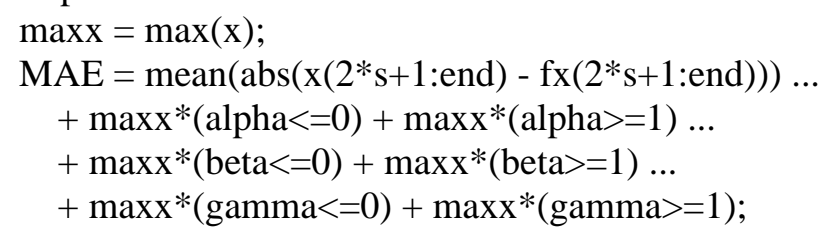




\subsection{Pengujian}

Berikut merupakan hasil uji dari fitur yang terdapat pada gambar 5 .

Tabel 1. Tabel uji Black box Fitur gambar 5

\begin{tabular}{|l|l|l|l|l|}
\hline No & Data Uji & Hasil test yang diharapkan & Output & Ket. \\
\hline $\mathbf{1}$ & $\begin{array}{l}\text { Memasukkan data } \\
\text { keuangan lengkap }\end{array}$ & $\begin{array}{l}\text { Muncul pesan bahwa data telah } \\
\text { disimpan di dalam database }\end{array}$ & $\begin{array}{l}\text { Muncul pesan bahwa } \\
\text { data telah disimpan di } \\
\text { dalam database }\end{array}$ & Sukses \\
\hline $\mathbf{2}$ & $\begin{array}{l}\text { Memasukkan data } \\
\text { keuangan tidak } \\
\text { lengkap }\end{array}$ & $\begin{array}{l}\text { Muncul pesan kesalahan bahwa } \\
\text { data yang kosong harus diisi }\end{array}$ & $\begin{array}{l}\text { Muncul pesan kesalahan } \\
\text { bahwa data yang kosong } \\
\text { harus diisi }\end{array}$ & Sukses \\
\hline $\mathbf{3}$ & $\begin{array}{l}\text { Mengubah data } \\
\text { keuangan }\end{array}$ & $\begin{array}{l}\text { Muncul form untuk mengubah } \\
\text { data admin }\end{array}$ & $\begin{array}{l}\text { Muncul form untuk } \\
\text { mengubah data admin }\end{array}$ & Sukses \\
\hline $\mathbf{4}$ & $\begin{array}{l}\text { Menghapus data } \\
\text { keuangan }\end{array}$ & $\begin{array}{l}\text { Muncul pesan data admin yakin } \\
\text { akan dihapus serta akan ada } \\
\text { pilihan oke dan batal }\end{array}$ & $\begin{array}{l}\text { Muncul pesan data admin } \\
\text { yakin akan dihapus serta } \\
\text { akan ada pilihan oke dan } \\
\text { batal }\end{array}$ & Sukses \\
\hline $\mathbf{5}$ & Mencetak excel & $\begin{array}{l}\text { Data terunduh dalam bentuk } \\
\text { excel (.xls) }\end{array}$ & $\begin{array}{l}\text { Data terunduh dalam } \\
\text { bentuk excel (.xls) }\end{array}$ & Sukses \\
\hline
\end{tabular}

Untuk menguji fitur pada gambar 6 juga menggunakan butir uji blackbox sebagai berikut:

Tabel 2. Tabel Uji Black Box Fitur gambar 6

\begin{tabular}{|l|l|l|l|l|}
\hline No & Data Uji & $\begin{array}{l}\text { Hasil test yang } \\
\text { diharapkan }\end{array}$ & Output \\
\hline 1 & $\begin{array}{l}\text { Menampilkan } \\
\text { Home Prediksi }\end{array}$ & $\begin{array}{l}\text { Muncul seluruh data } \\
\text { keuangan yang telah } \\
\text { dimasukkan }\end{array}$ & $\begin{array}{l}\text { Data yang telah } \\
\text { diinput tidak ada } \\
\text { yang tidak tampil }\end{array}$ & Sukses \\
\hline 2 & $\begin{array}{l}\text { Melakukan Proses } \\
\text { Perhitungan }\end{array}$ & Muncul hasil prediksi & $\begin{array}{l}\text { Muncul hasil } \\
\text { prediksi }\end{array}$ & Sukses \\
\hline
\end{tabular}

\section{HASIL}

\section{Metode Triple Exponential Smoothing}

Rumus untuk memprediksi keuntungan dengan metode triple exponential smoothing yaitu:

$\mathrm{Ft}+\mathrm{m}=\mathrm{at}+\mathrm{bt}(\mathrm{m})+1 / 2 \mathrm{ct}(\mathrm{m} 2)$

at merupakan nilai at pada panen ke-20

bt merupakan nilai bt pada panen ke-20

ct merupakan nilai ct pada panen ke-20

$\mathrm{m}$ merupakan prediksi untuk panen ke berapa, misalnya kita memprediksi untuk 2 panen selanjutnya maka $\mathrm{m}=2$

Perhitungan untuk 2 panen selanjutnya yaitu :

$\mathrm{Ft}+\mathrm{m}=\mathrm{at}+\mathrm{bt}(\mathrm{m})+1 / 2 \mathrm{ct}(\mathrm{m} 2)$

$\mathrm{F} 20+2=\mathrm{at}+\mathrm{bt}(2)+1 / 2 \mathrm{ct}(22)$

$=76,992,861.35+\{(4,316,984.46) *(2)\}+\left\{1 \frac{1}{2} *(361,942.37) *(22)\right\}$

$=86.350 .715$ 


\section{KILAT}

Vol. 8, No. 2, Oktober 2019, P-ISSN 2089-1245, E-ISSN 2655-4925

Nilai prediksi keuntungan untuk 2 panen selanjutnya menggunakan nilai $\alpha=0.3$ sebesar Rp. 86.350 .715 .

Untuk mengetahui skala nilai terkecil sampai terbesar, digunakan perhitungan prediksi untuk 2 panen selanjutnya dengan nilai $\alpha=0.1$ sampai $\alpha=0.9$. Cara perhitungan sama dengan mencari nilai prediksi menggunakan $\alpha=0.3$ di atas. Berikut diperoleh skala terkecil menggunakan nilai $\alpha$ berbeda.

Tabel 3. Skala Hasil Prediksi Menggunakan Triple Exponential Smoothing

\begin{tabular}{|c|r|r|}
\hline$\alpha$ & MAPE & $\begin{array}{c}\text { Prediksi 2 Panen } \\
\text { Selanjutnya }\end{array}$ \\
\hline 0.1 & 27.03 & Rp76,625,939 \\
\hline 0.2 & 18.38 & Rp79,855,264 \\
\hline 0.3 & 12.10 & Rp86,350,715 \\
\hline 0.4 & 15.13 & Rp79,235,083 \\
\hline 0.5 & 19.05 & Rp58,047,886 \\
\hline 0.6 & 26.15 & Rp25,620,007 \\
\hline 0.7 & 36.29 & - Rp17,472,861 \\
\hline 0.8 & 49.19 & - Rp71,955,275 \\
\hline 0.9 & 67.59 & - Rp139,640,917 \\
\hline
\end{tabular}

Dari tabel 3, dapat diketahui skala terkecil hingga skala terbesar prediksi untuk 2 panen selanjutnya. Nilai prediksi yang diambil yaitu nilai prediksi dengan nilai MAPE terkecil. Jadi, prediksi keuntungan menggunakan metode triple exponential smoothing untuk 2 panen selanjutnya sebesar Rp. 86.350.715 dengan nilai $\alpha=0.3$.

\section{PENUTUP}

Dengan menggunakan metode Triple Exponential Smoothing dapat melakukan prediksi keuntungan 2 panen selanjutnya didapat prediksi keuntungan menggunakan metode triple exponential smoothing sebesar Rp. 86.350.715.

perhitungan nilai mean absolute percentage error (MAPE), metode triple exponential smoothing menghasilkan nilai MAPE sebesar $12.10 \%$ dengan nilai $\alpha=0.3$ dan metode monte carlo menghasilkan nilai MAPE sebesar 40.58\%.

Menggunakan SDLC dari metode agile XP, peneliti dapat menghasilkan sebuah aplikasi dengan pengembangan yang cepat dan tepat.

\section{DAFTAR PUSTAKA}

[1] P. Jana, "Aplikasi Triple Exponential Smooting Untuk Forecasting Jumlah Penduduk Miskin," Jurnal Derivat, pp. 75-81, 2016.

[2] N. K. D. A. Jayanti, Y. P. Atmojo and I. G. N. Wiadnyana, "Penerapan Metode Triple Exponential Smoothing pada Sistem Peramalan Penentuan Stok Obat," Jurnal Sistem dan Informatika STMIK STIKOM Bali, pp. 13-25, 2015.

[3] V. A. Fitria and R. Hartono, "Peramalan Jumlah Penumpang Pada Siluet Tour And Travel Kota Malang Menggunakan Metode Triple Exponential Smoothing," Jurnal Ilmiah Teknologi dan Informasi ASIA, pp. 15-20, 2017.

[4] T. Aprilianto and I. Fauzi, "Perancangan Sistem Peramalan Penjualan Barang Pada UD Achmad Jaya Dengan Metode Triple Exponential Smoothing," Jurnal Ilmiah Teknologi dan Informatika ASIA, pp. 73-85, 2016. 
[5] R. S. Pressman, Software Engineering, A Practitioner's Appoarch, 7th Edition, McGraw Hill International Edition, 2010.

[6] S. S. A. S. B. P. K. M. K. D. A. S. P. V. M. Kuljeet Singh, "Implementation of Exponential Smoothing for Forecasting Time Series Data," International Journal of Scientific Research in Computer Science Applications and Management Studies, vol. Volume 8, no. Januari 2019, 2019.

[7] R. Niviani, Y. N. Nasution and N. A. Rizki, "Klasifikasi Persediaan Barang Menggunakan Analisis ALways Better Control (ABC) dan Prediksi Permintaan dengan Metode Monte Carlo (Studi Kasus: Persediaan Obat Pada Apotek Mega Rizki Tahun 2016)," Jurnal Eksponensial, pp. 103-110, 2017.

[8] Lusiana, S. Martha and S. W. Rizki, "Simulasi Pergerakan Harga Saham Menggunakan Pendekatan Metode Monte Carlo," Buletin Ilmiah Math, Stat,dan Terapannya (Bimaster), pp. 119-126, 2018. 